\title{
Pathogenesis of neuropathic foot ulcers in diabetes: understanding current concepts
}

\author{
Gayan Neomal Samarasinghe Ekanayake ${ }^{1}$, Suranga Ravinda Manilgama ${ }^{2}$ \\ ${ }^{1}$ National Hospital Sri Lanka \\ ${ }^{2}$ North Colombo Teaching Hospital, Sri Lanka
}

Keywords: Diabetic neuropathy; foot ulcers; deformity; callus formation; miccroangiopathy; microvascular disease

\section{Introduction}

The diabetic foot ulcer can occur in one out of four diabetic individuals during their lifetime [1]. Ischaemia, neuropathy, or a combination are the primary risk factors for non-healing foot ulcers. In the presence of these elements, even trivial trauma can trigger ulceration [2]. Moreover, neuropathy is associated with $85 \%$ of these ulcers [3] and ischaemia is associated with $10-60 \%$ in different case series [4]. Neuropathic foot ulcers can occur in three ways; deformity related trophic ulceration, trauma-Infection related nonhealing ulceration, superadded peripheral vascular diseaserelated ulceration.

This account is on the classic pathway of microangiopathy leading to peripheral neuropathy, deformity and ulceration. This group of patients will present with callus leading to ulceration. They represent $30 \%$ out of all types of diabetic foot ulcers [4].

\section{Diagnosis of neuropathic foot}

On examination, a classical hammertoe or clawfoot deformity [5] may be present in the advanced disease state. Although sensory, motor, autonomic components exist, testing for all the components is not essential. Thus clinically checking the protective sensation [testing with monofilament] and vibration sensation for the presence of diabetic peripheral neuropathy are useful [6]. However, this will be influenced by the thickness of the area of the foot test [7].
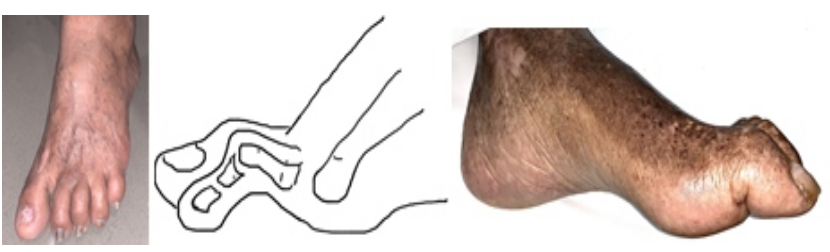

Figure 1. Claw toe and Hammer toe deformities

Correspondence: Gayan Neomal Samarasinghe Ekanayake

E-mail: Plastichandpics@gmail.com

(i) https://orcid.org/0000-0002-0839-4935

Received: 08-08-2021 Accepted: 27-11-2021

DOI: http://doi.org/10.4038/sljs.v39i3.8877

The Sri Lanka Journal of Surgery 2021; 39(3): 60-64

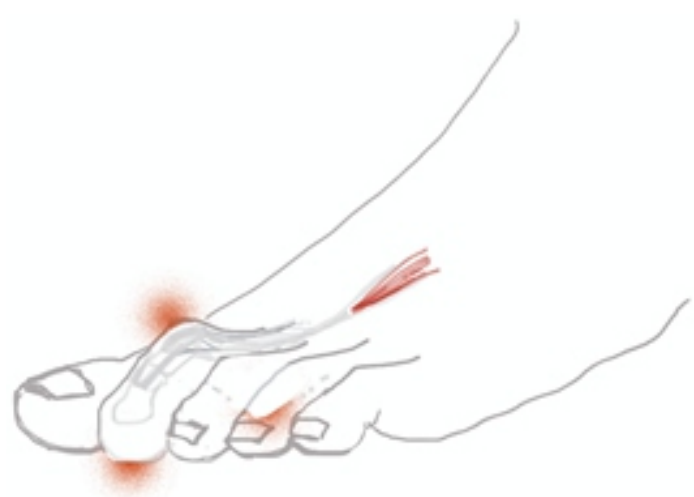

Figure 2. Abnormal pressure points

\begin{tabular}{|l|l|}
\hline & Pressure distribution in claw foot deformity. \\
\hline $\mathbf{1}$ & Tip of toes rather than the pulp of the toes. \\
\hline $\mathbf{2}$ & $\begin{array}{l}\text { Metacarpal heads compressing tissues proximal to } \\
\text { ball of foot, thickness of the plantar fascia and the } \\
\text { stiffness of soft tissues of these patients, can amplify } \\
\text { the pressure on the metatarsophalangeal joint, }\end{array}$ \\
\hline $\mathbf{3}$ & $\begin{array}{l}\text { Prominent PIP joints on the dorsal side [usually with } \\
\text { ill-fitting foot wear that can lead to repetitive } \\
\text { trauma]. In the background of sensory neuropathy } \\
\text { this can lead to ulceration. }\end{array}$ \\
\hline
\end{tabular}

\section{Clinical progression}

The hallmark of neuropathic foot disease is the deformity. This is described as a claw foot with loss of foot arches [6].

\section{The claw toe deformity [Figure 2]}

The clinical examination and radiological evidence show appearance of motor neuropathy effects in the small muscles of the foot. The characteristic fatty infiltration of intrinsic muscles seen on MRI is regarded as indirect evidence of the motor neuropathy. subsequent loss of lumbrical action produces the claw toe deformity with inability of the extending proximal interphalangeal joints. This is called intrinsic minus foot where the long flexors are unopposed at that joint $[5,6]$.

The claw deformity can be augmented by additional factors like joint capsule changes and plantar aponeurotic ruptures. 


\begin{tabular}{|r|l|}
\hline & Contributing factors are the. \\
\hline $\mathbf{1}$ & $\begin{array}{l}\text { Effect of tendoachillis shortening that plantar flex the foot and shifts more pressure to fore foot present in } \\
\text { diabetic patients particularly increase the pressure on the metatarsophalangeal joint }\end{array}$ \\
\hline $\mathbf{2}$ & Limited joint movements of subtalar joint and first metatarsophalangeal joint \\
\hline $\mathbf{3}$ & $\begin{array}{l}\text { Thickness of the plantar fascia and the stiffness of soft tissues of these patients, can amplify the pressure on } \\
\text { the metatarsophalangeal joint }\end{array}$ \\
\hline
\end{tabular}

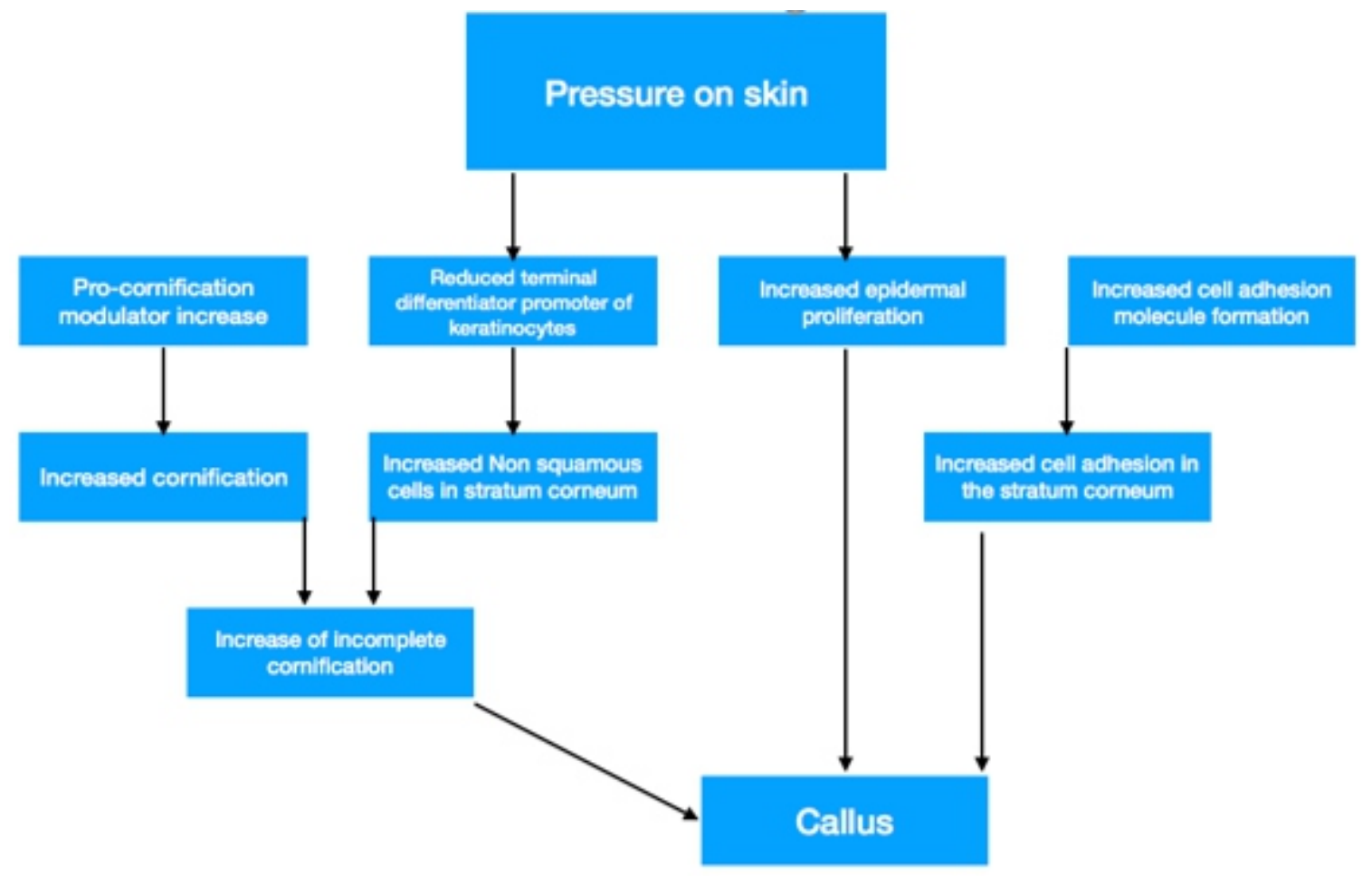

Figure 3. Bio-mechanical forces contributing to callus formation

The net effect of abnormal load experienced by metatarsophalangeal joints cause the retrograde buckling of metatarsal heads. This creates another foot deformity. This shifts the normal pressure points on the ball of the foot proximally in to the smooth glaberous instep region of the foot [8].

This part of the foot is not suitable to bear weight of the entire body unlike the ball of the foot. These deformities create three types of abnormal pressure points on the forefoot [9].

\section{Callus formation}

These changes of the skeleton will eventually affect the skin as it is the interphase between the skeleton and the surface that we walk on. When a thin skin that is not suitable for repeated pressure experiences this from both directions [vertical and frictional], it usually responds by focal vertical proliferation over the pressure areas. This response is supported by an increase in vascularity around the pressure point. This increased activity of the basal cell layer will push out more cells in too superficial layers. The natural process of producing granules of keratin that fills up the cell will form a thicker than normal keratin layer at the top. The natural shedding of this layer is slower at this area of hyperkeratosis [callus]. The biomechanical changes that accelerate callus formation are given in figure 3. The process is a complex genetic alteration that produces more keratinocytes that have an increased amount of keratin. This produces incomplete cornified cells that are resistant to desquamation than normal keratinocytes [10].

\section{Callus and infection}

Although this natural phenomenon is protective of the normal pressure points as a response to increasing pressure, the callus on the new pressure points will be mobile and may act as a different pressure point on the unprepared subcutaneous tissue. This abnormal friction between layers of skin and underlying tissue will produce a bursa known as an adventitious bursa. [Figure 5] Some authors have recognised the callus on a diabetic foot with deformities as a foreign body 


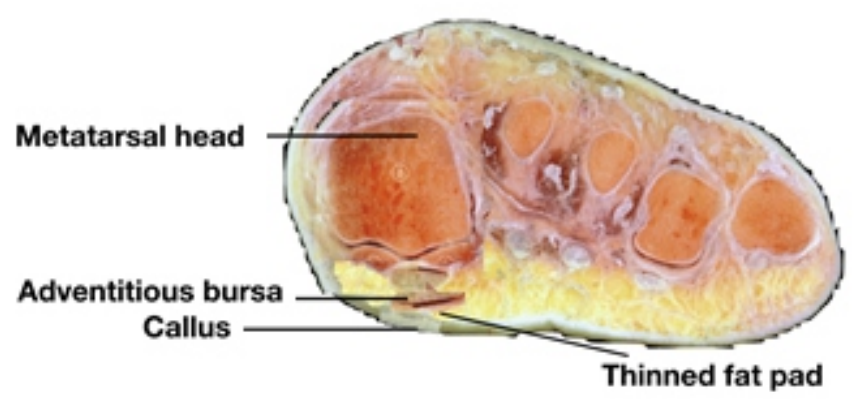

Figure 4. Pressure imbalances

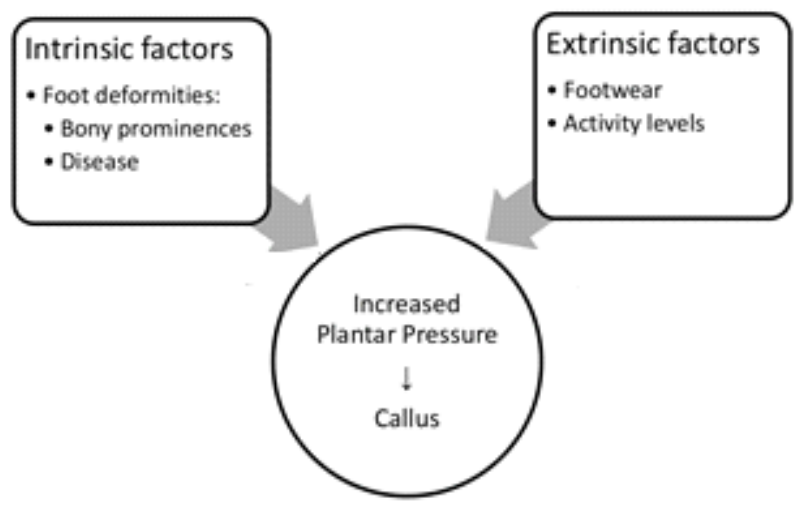

Figure 5. The cross sectional relationship of deformity to callus

that produce additional focal pressure on to deeper tissue. $[10,11,12,14]$

These calluses are prone to the effects of drying out as the water content or the moisture of the skin is also less in the background of decreased sweat gland activity of the plantar aspect and reduced sensation [15]. On magnification, there will be cracks on the callus that can even connect the already damaged underlying thin tissue layer or the adventitious bursa resulting from the callus itself. This step is the beginning of a vicious cycle of infection that can worsen the ulcer. At the initial stages, these infected cracks can be concealed by a thick callus till overt signs of infection take over the local tissue.

This simplified discussion on neuropathic ulcer development without superadded macrovascular disease is not complete without some understanding about the underlying pathogenesis of peripheral neuropathy due to hyperglycaemia.

\section{Peripheral neuropathy and Hyperglycaemia}

Diabetes Mellitus is identified as a derangement in metabolism characterised by prolonged hyperglycaemia due to abnormal insulin activity or/and insulin production. Longstanding hyperglycaemia results in alternations of the vascular structure and function leading to damage and failure of organ systems [17]. Two somewhat distinct vascular pathologies are described in longstanding diabetes: a small calibre vessel disease affecting the arterioles and capillary network of organs, and larger vessels disease [macroangiopathy] characterised by atherosclerosis in medium to major arteries. The scope of this section of the review is to discuss the pathogenesis of microangiopathy leading to peripheral diabetic neuropathy.

In general, neuropathy, nephropathy and retinopathy are considered microvascular complications of diabetes. Neuropathy seen in diabetes is a collection of neuropathies grouped according to the main fibre type affected [motor, sensory, and autonomic] and pattern of involvement of the body. Among these diabetic polyneuropathy [DPN] is the commonest form and the most common complication found among individuals with long-standing diabetes[17,19].

Distal diabetic neuropathy is characterised by axonal loss in multiple foci, which starts from distally that includes large and small diameter nerve fibres. Apart from axonal degeneration, decreased myelinated fibre numbers in crosssections, coexisting demyelination foci, regeneration of nerve fibres and re-myelination are also seen $[17,19]$.

Metabolic and vascular dysfunction are major contributors to the pathogenesis of DPN. An abnormal cascade of metabolic derangements due to chronic hyperglycaemia impacts adversely on nerve perfusion. The blood supply and the microvascular distribution of the nerve, consist of epineural and endoneurial circulation. Microcirculation is the basic functional unit responsible for maintaining perfusion pressure thus a steady supply of nutrients. It has a complex self-regulatory system controlling capillary permeability and small muscle tone changes affecting the calibre of vessels with its blood flow according to local metabolic demands [20,21]. The deranged biochemical state gives rise to microcirculatory dysfunction that eventually results in structural changes of nerves at the cellular level. These changes will produce a loss of function of affected nerves.

High glucose levels trigger a change in levels of nitric oxide [NO] bioavailability that counter reactive oxygen species [ROS] accumulation in the endothelium which eventually leads to its dysfunction[22,23]. This initial trigger signals several pathogenic pathways implicated in diabetic complications. These include elevated polyol pathway activity, nonenzymatic glycation, and protein kinase $\mathrm{C}$ levels that carry physical changes leading to microvascular complications [24].

Biochemical pathways activated in hyperglycaemia Irreversible nonenzymatic glycation of proteins cause 


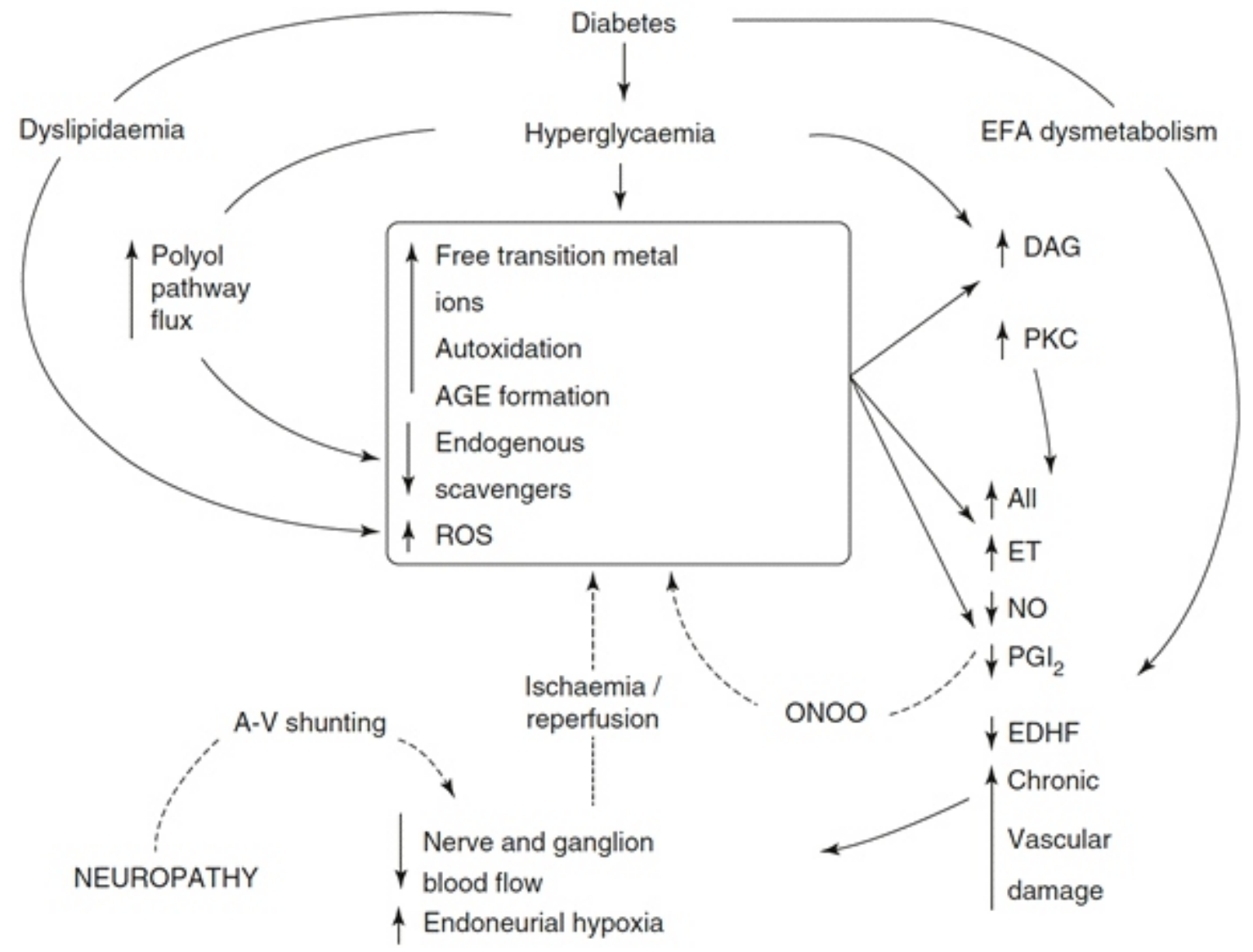

Figure 6. Alteration of metabolic pathways in hyperglycaemia. AII, angiotensin 2; AGE, advanced glycation end product; AV, arterio-venous; DAG, diacylglycerol; EDHF, endothelium-derived hyperpolarising factor; EFA, essential fatty acid; ET, endothelin-1; NO, nitric oxide; ONOO, peroxynitrite; PGI2, prostacyclin; PKC, protein kinase C; ROS, reactive oxygen species [18]. Adapted with permission from author

abnormalities of function by altering their molecular conformation, altering enzyme activity and disrupting receptor functions. These advanced glycated end-products [AGEs] are a heterogeneous group of molecules formed by the irreversible nonenzymatic glycation of plasma and cellular proteins. AGEs can amplify its disruption of cellular function by interfering with both intra and extracellular structure and function further cross-linking. This does not limit to proteins but also lipids and nucleic acids. These are responsible for various complications seen in diabetes [25]. This process is considered one of the initiating factors for nerve demyelination.

Protein kinase $\mathrm{C}$ is an enzyme present throughout the cell that plays a role in an array of intracellular signalling pathways. An important consequence of PKC activation is ROS generation. This ROS production and $\mathrm{PKC}$ ability to decrease eNOS activity amplify the cumulative effect of ROS on endothelial cells. The resulting abnormal accumulation of sorbitol in peripheral nerves causes depletion of myoinositol and a decrease in Na-K-ATPase levels adversely affects the nerve function [26].
Furthermore, the increased cellular glucose levels drive more glucose into the polyol pathway which is also known as the sorbitol pathway. Polyol pathway requires NADPH for aldose reductase as a substrate that reduces $\mathrm{NAD}+$ in the reaction in sorbitol reductase [26].

The alterations in the intracellular milieu and vasomotor functions result in structural vascular changes seen in microangiopathy; thickening of the capillary basement membrane, specific vascular cell apoptosis, hypoplasia and swelling of epithelial cells. These changes are seen mainly in the endoneurial vasa novorum with degeneration of pericytes, perivascular basement membrane thickness increase and microthrombi. These structural changes disrupt most of the cellular functions of vessels by increased permeability, changes in auto-regulation of blood flow to distal nerves. These were evident in vivo studies that show the endoneurial blood flow diverted to epineural circulation by shunting hence imparting steal phenomena. $[17,19,26]$.

All of the above pathological mechanisms collectively account for the development of distal peripheral neuropathy. 
All authors disclose no conflict of interest. The study was conducted in accordance with the ethical standards of the relevant institutional or national ethics committee and the Helsinki Declaration of 1975, as revised in 2000

\section{References}

1. Gregg EW, Sorlie P, Paulose-Ram R, et al. Prevalence of lowerextremity disease in the US adult population $>=40$ years of age with and without diabetes: 1999-2000 national health and nutrition examination survey. Diabetes Care. 2004;27[7]:15911597. https://doi.org/10.2337/diacare.27.7.1591

2. Baron R, Binder A, Wasner G. Neuropathic pain: diagnosis, pathophysiological mechanisms, and treatment. Lancet Neurol. 2010;9[8]:807-819. https://doi.org/10.1016/S1474-4422[10]70143-5

3. Jensen TS, Gottrup H, Sindrup SH, Bach FW. The clinical picture of neuropathic pain. Eur J Pharmacol. 2001;429[1-3]:1-11. https://doi.org/10.1016/S0014-2999[01]01302-4

4. Gregg EW, Sorlie P, Paulose-Ram R, et al. Prevalence of lowerextremity disease in the US adult population $>=40$ years of age with and without diabetes: 1999-2000 national health and nutrition examination survey. Diabetes Care. 2004;27[7]:15911597. https://doi.org/10.2337/diacare.27.7.1591

5. Schrier JC, Verheyen CC, Louwerens JW. Definitions of hammer toe and claw toe: an evaluation of the literature. J Am Podiatr Med Assoc. 2009;99[3]:194-197. https://doi.org/10.7547/0980194

6. Gooding GA, Stess RM, Graf PM, Moss KM, Louie KS, Grunfeld C. Sonography of the sole of the foot. Evidence for loss of foot pad thickness in diabetes and its relationship to ulceration of the foot. Invest Radiol. 1986;21[1]:45-48.

https://doi.org/10.1097/00004424-198601000-00008

7. Strzalkowski ND, Triano JJ, Lam CK, Templeton CA, Bent LR. Thresholds of skin sensitivity are partially influenced by mechanical properties of the skin on the foot sole. Physiol Rep. 2015;3[6]:e12425.

https://doi.org/10.14814/phy2.12425

8. Robertson DD, Mueller MJ, Smith KE, Commean PK, Pilgram T, Johnson JE. Structural changes in the forefoot of individuals with diabetes and a prior plantar ulcer. J Bone Joint Surg Am. 2002;84[8]:1395-1404. https://doi.org/10.2106/00004623-200208000-00016

9. Lavery LA, van Asten S, La Fontaine J. Clinical Examination and Risk Classification of the Diabetic Foot. In: Veves A, Giurini JM, Guzman RJ, editors. The Diabetic Foot: Medical and Surgical Management. Cham: Springer International Publishing; 2018. p. 19-30. https://doi.org/10.1007/978-3-319-89869-8_2

10. Wright CRF. The biophysical properties of plantar callus and the relationship between pressure and callus development and regression [PhD thesis]. Salford: University of Salford, Manchester; 2015.

11. Abouaesha F, van Schie CH, Griffths GD, Young RJ, Boulton AJ. Plantar tissue thickness is related to peak plantar pressure in the high-risk diabetic foot. Diabetes Care. 2001;24[7]:1270-1274. https://doi.org/10.2337/diacare.24.7.1270

12.Sun JH, Cheng BK, Zheng YP, Huang YP, Leung JY, Cheing GL. Changes in the thickness and stiffness of plantar soft tissues in people with diabetic peripheral neuropathy. Arch Phys Med Rehabil. 2011;92[9]:1484-1489.

https://doi.org/10.1016/j.apmr.2011.03.015

13.Jensen B, Leykum B, Fiorito J, Woodruff D, Bharara M, Armstrong DG. Adventitious bursae underlying chronic wounds: another possible deterrent to healing. Eplasty. 2012;12:e14.

14.Pataky Z, Golay A, Faravel L, et al. The impact of callosities on the magnitude and duration of plantar pressure in patients with diabetes mellitus. A callus may cause 18,600 kilograms of excess plantar pressure per day. Diabetes Metab. 2002;28[5]:356-361.

15.Ishibashi F, Kojima R, Kawasaki A, Yamanaka E, Kosaka A, Uetake H. Correlation between sudomotor function, sweat gland duct size and corneal nerve fiber pathology in patients with type 2 diabetes mellitus. J Diabetes Investig. 2014;5 [5]:588-596.

https://doi.org/10.1111/jdi.12171

16.Barrett EJ, Liu Z, Khamaisi M, et al. Diabetic Microvascular Disease: An Endocrine Society Scientific Statement. J Clin Endocrinol Metab. 2017;102[12]:4343-4410.

https://doi.org/10.1210/jc.2017-01922

17.Cameron NE, Eaton SE, Cotter MA, Tesfaye S. Vascular factors and metabolic interactions in the pathogenesis of diabetic neuropathy. Diabetologia. 2001;44[11]:1973-1988.

https://doi.org/10.1007/s001250100001

18. Yagihashi S, Mizukami H, Sugimoto K. Mechanism of diabetic neuropathy: Where are we now and where to go? J Diabetes Investig. 2011;2[1]:18-32.

https://doi.org/10.1111/j.2040-1124.2010.00070.x

19.Orasanu G, Plutzky J. The pathologic continuum of diabetic vascular disease. J Am Coll Cardiol. 2009;53[5 Suppl]:S35-S42. https://doi.org/10.1016/j.jacc.2008.09.055

20.Chawla A, Chawla R, Jaggi S. Microvasular and macrovascular complications in diabetes mellitus: Distinct or continuum? Indian J Endocrinol Metab. 2016;20[4]:546-551. https://doi.org/10.4103/2230-8210.183480

21.Creager MA, Lüscher TF, Cosentino F, Beckman JA. Diabetes and vascular disease: pathophysiology, clinical consequences, and medical therapy: Part I. Circulation. 2003;108[12]:15271532. https://doi.org/10.1161/01.CIR.0000091257.27563.32

22.Paneni F, Beckman JA, Creager MA, Cosentino F. Diabetes and vascular disease: pathophysiology, clinical consequences, and medical therapy: part I. Eur Heart J. 2013;34[31]:2436-2443. https://doi.org/10.1093/eurheartj/eht149

23.Jakus V, Rietbrock N. Advanced glycation end-products and the progress of diabetic vascular complications. Physiol Res. 2004;53[2]:131-142.

24.Singh VP, Bali A, Singh N, Jaggi AS. Advanced glycation end products and diabetic complications. Korean J Physiol Pharmacol. 2014;18[1]:1-14. https://doi.org/10.4196/kjpp.2014.18.1.1

25.Brownlee M. Biochemistry and molecular cell biology of diabetic complications. Nature. 2001;414[6865]:813-820. https://doi.org/10.1038/414813a

26.Tesfaye S, Wu J. Diabetic neuropathy. In: Veves A, Giurini JM, Guzman RJ, editors. The Diabetic Foot: Medical and Surgical Management. Cham: Springer International Publishing; 2018. p. $31-46$.

https://doi.org/10.1007/978-3-319-89869-8_3 